\title{
Hyperfibrinolysis diagnosed with rotational thromboelastometry and treated with tranexamic acid in a dog with acute traumatic coagulopathy
}

\author{
Muri, Benjamin ; Schmierer, Philipp A ; Schwarz, Andrea ; Sigrist, Nadja
}

\begin{abstract}
A 4-year old male Australian Cattle Dog involved in a road traffic accident was presented with severe polytrauma to the Small Animal Clinic, University of Zurich. He was presented in hemorrhagic shock, with an initial lactate of $10.3 \mathrm{mmol} / \mathrm{l}$ and ongoing bleeding from multiple injury sites. Acute traumatic coagulopathy diagnosed with ROTEM within one hour after accident showed marked hypocoagulation and hyperfibrinolysis. Treatment with a total dose of $40 \mathrm{mg} / \mathrm{kg}$ of tranexamic acid intravenously resulted in successful elimination of hyperfibrinolysis in the following, serially measured ROTEM tracings.
\end{abstract}

DOI: https://doi.org/10.17236/sat00155

Other titles: Diagnose von Hyperfibrinolyse mittels Rotations-Thromboelastometrie und Behandlung mit Tranexamsäure bei einem Hund mit akuter traumatischer Koagulopathie

Posted at the Zurich Open Repository and Archive, University of Zurich

ZORA URL: https://doi.org/10.5167/uzh-158771

Journal Article

Published Version

Originally published at:

Muri, Benjamin; Schmierer, Philipp A; Schwarz, Andrea; Sigrist, Nadja (2018). Hyperfibrinolysis diagnosed with rotational thromboelastometry and treated with tranexamic acid in a dog with acute traumatic coagulopathy. Schweizer Archiv für Tierheilkunde, 160(4):227-233.

DOI: https://doi.org/10.17236/sat00155 


\title{
Hyperfibrinolysis diagnosed with rota- tional thromboelastometry and treated with tranexamic acid in a dog with acute traumatic coagulopathy
}

\author{
B. Muri', P. Schmierer ${ }^{2}$, A. Schwarz ${ }^{3}$, N. Sigrist ${ }^{1}$ \\ ${ }^{1}$ Department for Small Animals, ${ }^{2}$ Clinic of Small Animal Surgery and ${ }^{3}$ Section of Anesthesiology, Equine \\ Department, Vetsuisse Faculty, University of Zurich, Switzerland
}

\begin{abstract}
Summary
A 4-year old male Australian Cattle Dog involved in a road traffic accident was presented with severe polytrauma to the Small Animal Clinic, University of Zurich. He was presented in hemorrhagic shock, with an initial lactate of $10.3 \mathrm{mmol} / \mathrm{l}$ and ongoing bleeding from multiple injury sites. Acute traumatic coagulopathy diagnosed with ROTEM within one hour after accident showed marked hypocoagulation and hyperfibrinolysis. Treatment with a total dose of $40 \mathrm{mg} / \mathrm{kg}$ of tranexamic acid intravenously resulted in successful elimination of hyperfibrinolysis in the following, serially measured ROTEM tracings.
\end{abstract}

Keywords: canine, ATC, trauma, fibrinolysis, ROTEM
Diagnose von Hyperfibrinolyse mittels Rotations-Thromboelastometrie und Behandlung mit Tranexamsäure bei einem Hund mit akuter traumatischer Koagulopathie

Ein 4-jähriger, männlicher Australian Cattle Dog wurde mit schwerem Polytrauma nach einem Verkehrsunfall an der Kleitierklinik der Universität Zürich vorgestellt. Er war in hämorrhagischem Schock, hatte mehrere blutende Wunden und ein Laktat von $10.3 \mathrm{mmol} / 1$ bei Eintritt. Die akute Traumatische Koagulopathie (ATC) wurde mittels Rotationeller Thromboelastometrie (ROTEM) diagnostiziert und zeigte sich in markanter Hypokoagulabilität und Hyperfibrinolyse. Die Behandlung mit insgesamt $40 \mathrm{mg} / \mathrm{kg}$ Tranexamsäure i.v. resultierte in einer erfolgreichen Therapie der Hyperfibrinolyse in den folgenden, seriell gemessenen ROTEM Untersuchungen.

Schlüsselwörter: Hund, ATC, Trauma, Fibrinolyse, ROTEM https://doi.org/ 10.17236/sat00155

Received: 30.08 .2017 Accepted: 14.11.2017

\section{Introduction}

Acute traumatic coagulopathy (ATC) describes a systemic coagulopathy following trauma. It is thought to result from tissue injury in combination with hypoperfusion and systemic inflammation, followed by a dynamic and complex process. Hypothermia, acidosis and hemodilution further impair the initiated coagulopathy (Brohi, et al., 2007; Frith, et al., 2010; Cohen, et al., 2013; Davenport, et al., 2016;). ATC can be characterized by hypercoagulation, hypocoagulation and hyperfibrinolysis, varying with increased injury severity and depending on time after injury (Dobson, et al., 2015). ATC occurs in up to $30 \%$ of the severely injured human trauma patients and increases mortality at least fourfold (Brohi, et al., 2003; Maegele, et al., 2007; Frith, et al., 2010).

The diagnosis of ATC remains controversial, as there is no standardized and globally established test in human or veterinary medicine. Traditional coagulation tests like activated partial thromboplastin time (aPTT) and prothrombin time (PT) have been used along with platelet count and serum fibrinogen measurements to diagnose ATC (Cohen, et al., 2013). Viscoelastic tests such as rotational thromboelastometry (ROTEM) or thromboelastography (TEG) may be superior to assess coagulation in ATC, as they not only assess plasmatic coagulation, 
Hyperfibrinolysis diagnosed with rotational thromboelastometry and treated with tranexamic acid in a dog with acute traumatic coagulopathy

B. Muri et al. but also the formation and strength of the formed clot and its lysis (Frith, et al., 2010; Davenport, et al., 2011; Hagemo, et al., 2015; Rossaint, et al., 2016).

The ROTEM device (ROTEM delta, Pentapharm GmbH D-81829 München) measures the viscoelastic properties of whole blood under low shear conditions. The changes in viscoelasticity are visualized in a tracing and several parameters are automatically determined. The clotting time (CT) describes the time until fibrin formation starts and is comparable to PT and aPTT. The clot formation time (CFT) is determined by the kinetics of clot formation and depends mainly on fibrinogen concentration and thrombocytes numbers. The maximum clot firmness (MCF) describes the maximal strength of the fibrin/thrombocytes clot. Fibrinolysis can be assessed with the maximum lysis (ML). Several coagulation activators can be used. The ExTEM test measures clot formation by activation of the coagulation cascade through proprietary tissue factor (extrinsic pathway) while the InTEM uses phospholipids and ellagic acid and activates coagulation via intrinsic pathway. In the ApTEM test, fibrinolysis is inhibited by added aprotinin, an antifibrinolytic, to the ExTEM reagent. The FibTEM tracing enables determination of fibrinogen by added cytochalasin D, a platelet inhibitor, to the ExTEM reagent (Spiel, et al., 2006).

In veterinary medicine there are only a few studies investigating ATC in canine trauma patients (Mischke, 2005; Abelson, et al., 2013; Holowaychuck, et al., 2014; Gottlieb, et al., 2016;) and most information regarding diagnosis and pathophysiology is derived from human medicine. To our knowledge, hyperfibrinolysis identified with ROTEM has not yet been described in canine trauma patients.

\section{Case History}

\section{Physical examination}

A 4-year old, male Australian cattle dog was presented to the emergency service of the Small Animal Clinic University of Zurich within fifteen minutes after being hit by bus. The dog was severely injured (Animal trauma triage score 13/18 (Rockar and 1994)) and presented in lateral recumbency. At presentation, the dog showed pale mucus membranes, a capillary refill time (CRT) of 3 seconds, a weak femoral pulse, a heart rate of $200 \mathrm{bpm}$ and a rectal temperature of $39.2^{\circ} \mathrm{C}$. Respiratory rate (RR) was $24 / \mathrm{min}$, with regular thoracic movements and unremarkable lung auscultation. There was a large area of anatomical degloving of the left abdominal wall, a ventral abdominal wall defect with evisceration of intestinal loops, a traumatic prepubic hernia with violation of the right vascular lacuna and laceration of the femoral artery and vein with active bleeding. Multiple, severe soft tissue lesions with muscular tear and diffuse bleeding of adductor muscles of the right thigh were noted.

\section{Therapy}

Oxygen was supplemented by face mask, a peripheral venous catheter was inserted and a stat acid-base analysis (RAPIDPoint 500, Siemens Schweiz AG) was performed. The dog received $4 \mathrm{ml} / \mathrm{kg}$ of $7.2 \% \mathrm{NaCl}$ (Natriumchlorid „Bichsel“ 7.2\%, Dr. G. Bichsel AG, 3800 Interlaken), $10 \mathrm{ml} / \mathrm{kg}$ of Ringer's acetate (Ringer-Acetat Fresenius i.v., Fresenius Kabi, 6370 Oberdorf) and $5 \mathrm{ml} / \mathrm{kg}$ of hydroxyethyl starch (Voluven $6 \%$ balanced i.v., Fresenius Kabi, 6370 Oberdorf) as boluses over approximately five minutes each. The first detectable blood pressure during fluid resuscitation was $40 \mathrm{mmHg}$ measured by Doppler. The dog further received $20 \mathrm{mg} / \mathrm{kg}$ of tranexamic acid (Cyclokapron ${ }^{\circledR}$, Pfizer Corporation Austria, $1210 \mathrm{Wien}$ ), $0.2 \mathrm{mg} / \mathrm{kg}$ of methadone (Metha-

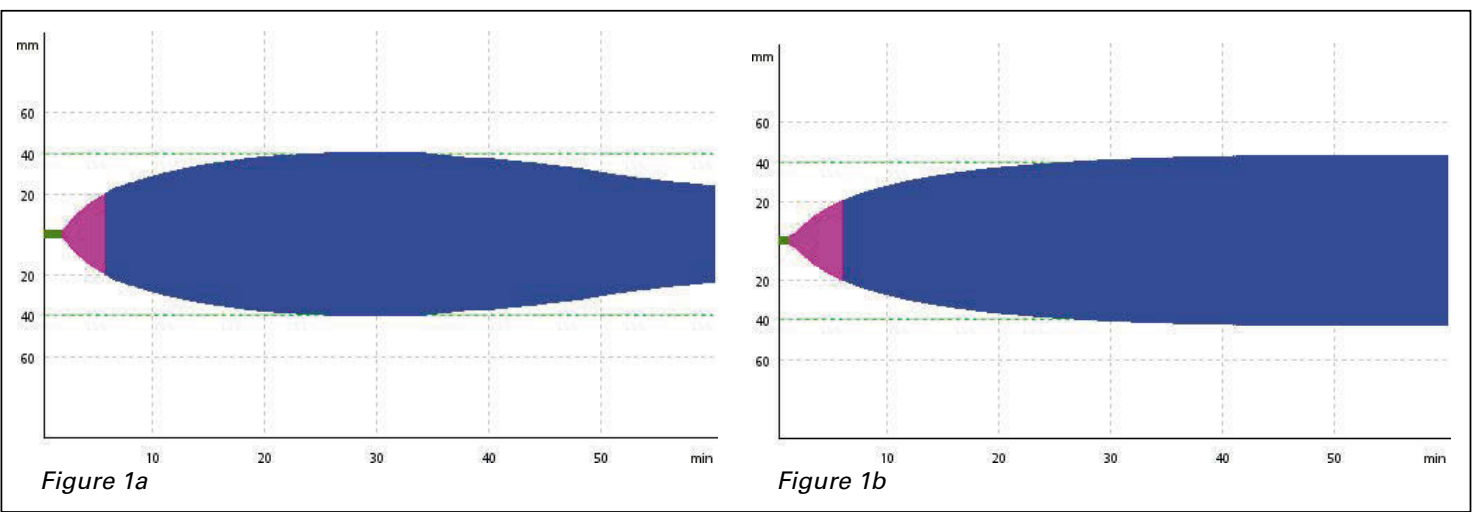

Figure 1: ExTEM (1a) and ApTEM (1b) profile of a dog with acute traumatic coagulopathy after initial therapy. Both profiles show hypocoaguability with a maximum clot firmness of $40 \mathrm{~mm}$ in ExTEM. The ExTEM profile shows hyperfibrinolysis, starting after 30 minutes. Lysis cannot be seen in the ApTEM, suggesting the identified lysis in the ExTEM profile represents true hyperfibrinolysis (Ganter, 2008) 
Table 1: Blood Values (Blood gas, $\mathrm{CBC}$ and clinical Chemistry) at different time points during hospital stay.

\begin{tabular}{|c|c|c|c|c|c|c|c|c|}
\hline Time after admission [h:min] & & $0: 0$ & $0: 15$ & $03: 06^{*}$ & $9: 40$ & $15: 00^{* *}$ & $24: 00$ & 48:00 \\
\hline & $\begin{array}{c}\text { Reference } \\
\text { interval }\end{array}$ & & & & & & & \\
\hline $\begin{array}{l}\text { Blood Gas } \\
\text { [V: venous; A:arterial] }\end{array}$ & V & V & V & V & V & V & $A$ & $A$ \\
\hline $\mathrm{pH}$ & $7,35-7,45$ & 7,21 & 7,21 & 7,28 & 7,37 & 7,31 & 7,34 & 7,25 \\
\hline $\mathrm{pCO} 2[\mathrm{mmHg}]$ & $29-43$ & 29,4 & 32,4 & 41,6 & 40,1 & 39,1 & 33,5 & 25,8 \\
\hline pO2 [mmHg] & $30-53$ & 72,4 & 135,8 & 58,3 & 54,1 & 33,9 & 100,2 & 95,7 \\
\hline $\mathrm{HCO} 3$ - std [mmol/I] & $20-25$ & 13,9 & 13,6 & 18,5 & 22,4 & 18,8 & 18,4 & 13 \\
\hline $\mathrm{BE}(\mathrm{B})[\mathrm{mmol} / \mathrm{l}]$ & $-7-2$ & $-14,5$ & -14 & $-7,1$ & $-2,3$ & $-6,2$ & $-7,3$ & $-14,6$ \\
\hline Hct [\%] & $35-61$ & 60 & 33 & 40 & $\mathrm{~N} / \mathrm{A}$ & 23 & 21 & 28 \\
\hline $\mathrm{K}+[\mathrm{mmol} / \mathrm{I}]$ & $3,6-4,7$ & 3,97 & 3,84 & 4,49 & 4,52 & 4,37 & 3,46 & 3,60 \\
\hline $\mathrm{Ca}++[\mathrm{mmol} / \mathrm{l}]$ & $1,21-1,41$ & 1,23 & 1,03 & 1,09 & 1,45 & 1,21 & 1,23 & 1,24 \\
\hline Glu [mmol/l] & $3,9-6,6$ & 15 & 10,6 & 13,1 & 5,3 & 6,7 & 6,7 & 6,4 \\
\hline Lac [mmol/l] & $0,42-2,13$ & 10,36 & 6,53 & 3,35 & 2,61 & 1,48 & 1,18 & 2,94 \\
\hline \multicolumn{9}{|l|}{ CBC } \\
\hline Hct [\%] & $42-55$ & & 30 & & 29 & & 19 & \\
\hline Leukocytes *10E3/ul & $4,7-11,3$ & & 3,2 & & & & 6,2 & 0,6 \\
\hline Thrombocytes *10E3/ul & & & 108 & & & & 64 & \\
\hline \multicolumn{9}{|l|}{ Clinical Chemistry } \\
\hline Alb g/l & $29-37$ & & 12 & & 6 & 21 & 20 & 14 \\
\hline
\end{tabular}

* Whole Blood Transfusion at 1:30h $(22 \mathrm{ml} / \mathrm{kg})$; Surgery from approximately 3:00 to 8:30h;

* 20\% Human Serum Albumin Transfusion (1 $/ \mathrm{kg})$ at 10:30h.

BE (B): Base Excess of Blood; Hct: Hematocrit; Glu: Dextrose; Lac: Lactate; Alb: Albumin; N/A: not available. CBC: Complete Blood Count, performed automatically on a Sysmex XT 2000i (Sysmex digitana, CH-Horgen). Clinical Chemistry was performed on a Cobas 6000 (Cobas 6000. Roche Diagnostics AG, CH-Rotkreuz)

Table 2: Different ROTEM Tracings (ExTEM, ApTEM, FibTEM) after 0:15h, 9:40h, 24h and 48h.

\begin{tabular}{|c|c|c|c|c|c|c|c|c|c|c|c|}
\hline \multirow[b]{2}{*}{ Parameter } & \multicolumn{5}{|c|}{ EXTEM } & \multicolumn{4}{|c|}{ APTEM } & \multicolumn{2}{|c|}{ FIBTEM } \\
\hline & $\begin{array}{l}\text { A5 } \\
{[\mathrm{mm}]}\end{array}$ & $\begin{array}{l}\text { CT } \\
\text { [sec] }\end{array}$ & $\begin{array}{l}\text { CFT } \\
{[\mathrm{sec}]}\end{array}$ & $\begin{array}{l}\text { MCF } \\
{[\mathrm{mm}]}\end{array}$ & $\begin{array}{l}\mathrm{ML} \\
{[\%]}\end{array}$ & $\begin{array}{l}\text { CT } \\
{[\mathrm{sec}]}\end{array}$ & $\begin{array}{l}\text { CFT } \\
{[\mathrm{sec}]}\end{array}$ & $\begin{array}{l}\text { MCF } \\
{[\mathrm{mm}]}\end{array}$ & $\begin{array}{l}\text { ML } \\
{[\%]}\end{array}$ & $\begin{array}{l}\text { CT } \\
{[\mathrm{sec}]}\end{array}$ & $\begin{array}{l}\mathrm{MCF} \\
{[\mathrm{mm}]}\end{array}$ \\
\hline $\begin{array}{l}\text { Reference } \\
\text { interval* }\end{array}$ & $\mathrm{N} / \mathrm{A}$ & $26-57$ & 53-153 & $46-62$ & $0-10$ & $31-59$ & $67-164$ & $52-65$ & $0-3$ & $35-108$ & $3-9$ \\
\hline $0: 15 \mathrm{~h}$ & 23 & 111 & 229 & 40 & 41 & 65 & 285 & 43 & 1 & 163 & 4 \\
\hline $9: 40 \mathrm{~h}$ & 25 & 47 & 210 & 48 & 1 & 54 & 228 & 46 & 1 & 154 & 5 \\
\hline $24 \mathrm{~h}$ & 26 & 47 & 210 & 51 & 0 & 55 & 237 & 48 & 1 & 61 & 5 \\
\hline $48 \mathrm{~h}$ & & & & & & & & & & 135 & 4 \\
\hline
\end{tabular}

* in-house references

A5: Amplitude 5min after CT; CT: Clotting Time; CFT: Clot Formation Time; MCF: Maximum Clot Firmness; ML: Maximum Lysis

don Streuli ${ }^{\circledR}$, Streuli Pharma AG, 8730 Uznach) and $20 \mathrm{mg} / \mathrm{kg}$ of ampicillin-sulbactam (Ampicillin/Sulbactam 1000mg/500mg, Aurobindo Pharma GmbH, 81829 München). After this initial therapy, another blood sample was analyzed. Initial blood results are listed in Table 1.

\section{Thromboelastometry}

ROTEM analysis showed decreased clot strength and prolonged clotting time (Tab. 2). In the ExTEM tracing, hyperfibrinolysis with ML of $41 \%$ (reference interval $0-10 \%$ ) was detected. The ApTEM tracing showed a ML
Hyperfibrinolysis diagnosed with rotational thromboelastometry and treated with tranexamic acid in a dog with acute traumatic coagulopathy B. Muri et al. of $1 \%$ (reference interval $0-3 \%$ ), confirming hyperfibrinolysis (Fig. 1). Fibtem MCF was $4 \mathrm{~mm}$ (reference interval: $3-9 \mathrm{~mm}$ ). Based on these findings, tranexamic acid $(20 \mathrm{mg} / \mathrm{kg})$ was repeated one hour after the first dose.

The dog was further stabilized and the right A. /V. femoralis were cross clamped with haemostats and ligated to control the ongoing bleeding. The eviscerated intestines and wounds were covered with sterile moist abdominal sponges. 
Hyperfibrinolysis diagnosed with rotational thromboelastometry and treated with tranexamic acid in a dog with acute traumatic coagulopathy

B. Muri et al.

\section{Diagnostic imaging and surgery}

Fifty minutes after admission a whole body CT study was performed. The CT revealed multiple pelvic fractures, right fibula and tibia fractures, complete musculus rectus abdominis avulsion, free abdominal gas, but no detectable lesion of the skull, spine or thorax.

After receiving a unit of matched fresh whole blood $(22 \mathrm{ml} / \mathrm{kg})$, anaesthesia was co-induced with ketamin $5 \mathrm{mg} / \mathrm{kg}$ (Ketanarkon 100, Streuli Pharma AG, 8730 Uznach) and midazolam $0.25 \mathrm{mg} / \mathrm{kg}$ (Dormicum ${ }^{\circledR}$, Roche Pharma (Schweiz) AG, 4153 Reinach) and maintained with sevoflurane in air/oxygen (1:1). Intra-operative analgesia was provided by lidocain $(1.8 \mathrm{mg} / \mathrm{kg} / \mathrm{h})$ (Lidocain $\mathrm{HCl}$ „Bichsel“ 2\%, Dr. G Bichsel AG, 3800 Interlaken), fentanyl $(0,25 \mathrm{ug} / \mathrm{kg} / \mathrm{h})$ (Fentanyl Sintetica, Sintetica AG, CH-6850 Mendrisio) and ketamin (0.6mg/ $\mathrm{kg} / \mathrm{h}$ ). During the anaesthesia of about 8 hours, the dog was cardiovascularly stable with a mean arterial blood pressure (MAP) of $>70 \mathrm{mmHg}$ throughout anaesthesia. Despite active warming following induction, rectal body temperature dropped to $34.4{ }^{\circ} \mathrm{C}$ during anaesthesia. During and after surgery, follow-up arterial blood gas analyses (Tab. 1) were performed and electrolyte abnormalities were corrected. Exploration of the abdomen was performed. The eviscerated intestinal bundle was copiously rinsed with warm Ringer's acetate before transferred back in the abdominal cavity. Resection and anastomosis of approximately $70 \mathrm{~cm}$ of mid jejunum was performed due to avulsion of mesentery and associated vasculature and a partial omentectomy was performed. The complete avulsion of the tendo prepubicus was fixed to the pelvis with four drill holes and non-absorbable suture size 1 (Prolene ${ }^{\circledR}$, Ethicon, Somerville, NJ 08876). The inguinal wound was lavaged and the right A./V. femoralis was sealed proximal to the ligation with an electrothermal bipolar tissue sealing system (LigaSure ${ }^{\circledR}$, Covidien Medtronic plc, Dublin Ireland). The adductor muscles were debrided and repositioned and three active drains (Blake ${ }^{\circledR}$, Ethicon, Somerville NJ 08876) were placed.. Following closure of the abdomen, a vacuum assisted closure system (V.A.C ${ }^{\circledR}$, KCI medical, San Antonio, TX 78265) was placed on the degloving defect on the flank. Intraoperatively, the bleeding from major vessels was controlled and diffuse bleeding from the peritoneal surface was noted.

\section{Postoperative care}

Approximately 10 hours after admission the dog was transferred to the intensive care unit, where another blood sample was taken from the indwelling central venous catheter for ROTEM analysis and determination of serum albumin concentration. At this time, the patient had received a total of $40 \mathrm{mg} / \mathrm{kg}$ of tranexamic acid, $22 \mathrm{ml} / \mathrm{kg}$ of whole fresh blood, $98 \mathrm{ml} / \mathrm{kg}$ of crystalloids (Ringer's acetate) and $24 \mathrm{ml} / \mathrm{kg}$ colloids (Voluven). The
FibTEM and ExTEM tracings were, except for the CFT and Alpha Angle of the ExTEM, within normal limits (Tab. 2). Hematocrit was 29\% (reference interval 42$55 \%$ ) and serum albumin concentration was $6 \mathrm{~g} / 1$ (reference interval 29-37 $\mathrm{g} / \mathrm{l}$ ). Subsequently, the dog was transfused with $1 \mathrm{~g} / \mathrm{kg} 20 \%$ human serum albumin (Albumin CSL 20\%, CSL Behring AG, 3014 Bern), which increased serum albumin concentration to $21 \mathrm{~g} / \mathrm{l}$. The dog additionally received paracetamol $(10 \mathrm{mg} / \mathrm{kg}, \mathrm{q} 8 \mathrm{~h})$ (Paracetamol Fresenius, Fresenius Kabi, 6370 Oberdorf) as an analgesic.

During the following 12 hours, the dog was cardiovascularly stable. The diffuse bleeding from the inguinal space diminished clinically approximately one hour after surgical intervention and administration of $40 \mathrm{mg} / \mathrm{kg}$ of tranexamic acid and no further clinical signs of bleeding were identified. $24 \mathrm{~h}$ after admission another ROTEM analysis was performed (Tab. 2). Following ROTEM analysis, tranexamic acid was given one more time and was then discontinued, as hyperfibrinolysis was not detected anymore. The dog received $10 \mathrm{ml} / \mathrm{kg}$ of cross matched concentrated red blood cells, increasing the hematocrit from $19 \%$ to $38 \%$. 48h after admission, a CBC showed severe leucopenia and left shift (Tab. 1). The dog developed hypoglycaemia, MAP dropped to $<60 \mathrm{mmHg}$ and did not react to repeated fluid boluses with Ringer's acetate (total of $60 \mathrm{ml} / \mathrm{kg}$ ) and Voluven $(3 \mathrm{ml} / \mathrm{kg})$. Cytological evaluation of $\mathrm{ab}$ dominal fluid confirmed a septic abdomen with extraand intracellular bacteria. At this time point, the owner elected for euthanasia. No post-mortem analysis was performed.

\section{Discussion}

Acute traumatic coagulopathy is a complication of trauma leading to coagulopathy and clinical bleeding diathesis followed by increased transfusion requirement and increased mortality (MacLeod, et al., 2003; Brohi, et al., 2003; Maegele, et al., 2007; Frith, et al., 2010; Davenport, et al., 2011). The coagulopathy is characterized by tissue damage through trauma and concurrent hypoperfusion, leading to a complex and dynamic activation and inhibition of several steps of haemostasis (Dobson, et al., 2015; Davenport and Brohi, 2016).

Hyperfibrinolysis is a common finding in people with severe trauma (Raza, et al., 2013; Cardenas, et al., 2014). The polytraumatised dog in our study showed marked hyperfibrinolysis which was identified by an increased ML starting 30 minutes after activation of the ExTEM tracing. Hyperfibrinolysis seen in the ExTEM tracing of our dog is supported by concurrent evaluation of the ApTEM profile, which did not show hyperfibrinolysis. 
The comparison of the ApTEM to the ExTEM profile allows the diagnosis of hyperfibrinolysis in bleeding human patients, as lysis is inhibited in the ApTEM reagent by the addition of aprotinin, an antifibrinolytic (Ganter, 2008). To our knowledge, this is the first description of trauma-induced hyperfibrinolysis in a native blood sample and proven by concurrent ApTEM analysis. A previous case report suspected trauma-induced hyperfibrinolysis in frozen plasma samples that were activated with tissue plasminogen activator (Yoo, et al., 2016).

Hyperfibrinolysis is also not commonly identified in dogs with other diseases. It has been described in dogs with spontaneous (non-traumatic) haemoperitoneum (Fletcher, et al., 2015) and in dogs with Angiostrongylus vasorum infection (Sigrist, et al., 2017). The treatment of choice for hyperfibrinolysis is an antifibrinolytic drug, such as tranexamic acid (CRASH-2 trial collaborators, 2010). The presented dog initially received $20 \mathrm{mg} / \mathrm{kg}$ of tranexamic acid IV. The dose of tranexamic acid was empirically deduced from human data and own clinical experience. To our knowledge, no pharmacological evaluation of the minimal required dose to inhibit hyperfibrinolysis in dogs has been performed. As hyperfibrinolysis was still present on the first ROTEM analysis, despite administration of $20 \mathrm{mg} / \mathrm{kg}$ tranexamic acid five to ten minutes prior to blood sampling, we suspected that the patient needed more than $20 \mathrm{mg} / \mathrm{kg}$. While we cannot exclude that the maximal drug effect was not reached after 10 minutes, the finding of the need of higher dosages of tranexamic acid in dogs with overt hyperfibrinolysis and clinical signs of bleeding diathesis is in accordance with findings in dogs with hyperfibrinolysis for other reasons (Sigrist, et al., 2017). Potentially, the identified hyperfibrinolysis of this dog may have been even more significant prior to tranexamic acid administration. Hyperfibrinolysis was no longer detectable on ROTEM tracings after the second dose of tranexamic acid, however, no ROTEM analysis was available immediately after the second dose of tranexamic acid and prior to whole blood transfusion, which may have had an effect on hyperfibrinolysis as well. Additionally, no ROTEM analysis is available after weaning of the drug, so no conclusion can be drawn regarding the time frame of hyperfibrinolysis and the need for continued tranexamic acid supplementation in dogs with hyperfibrinolysis. The human European trauma guidelines recommend early $(<3 \mathrm{~h}$ after injury) treatment with tranexamic acid until bleeding diminishes.

ATC is further characterized by hypocoagulation, which was identified in our dog as well. Decreased MCF, prolonged CT and prolonged CFT were identified in the first ExTEM. Since the dog received fluid therapy prior to blood sampling for ROTEM analysis at presentation, we cannot exclude a dilutional or hypocoaguable effect seen with colloids and hypertonic saline. However, doses were lower than those administered in studies that showed significant effect on ROTEM parameters compared to dilution alone (Adamik, et al., 2015; Reuteler et al., 2017). As described above, tissue trauma in combination with hypoperfusion are the main causes for developing ATC. Rising injury severity is associated with the severity of hypocoagulation and hyperfibrinolysis (Brohi, et al., 2008; Frith, et al., 2010). In a study with 40 dogs (Holowaychuck, et al., 2014), the finding of ATC, defined as two or more abnormal coagulation tests, was more common in dogs with higher injury severity. The presented dog was severely polytraumatised, with an ATT score of 13/18 (Rockar, et al., 1994), and also severely hypoperfused at presentation, with a serum lactate of $10.3 \mathrm{mmol} / 1$ and clinical signs of hypovolaemic shock in addition to a non measurable blood pressure. In addition to tissue trauma and hypoperfusion leading to development of ACT, several factors are known to contribute to the coagulopathy: acidosis, hypothermia and hemodilution. Mild acidosis was present at admission with a $\mathrm{pH}$ of 7.21, which might have had a worsening effect on coagulation measured by ROTEM (Engstrom, et al., 2006; Dirkmann, et al., 2008) and, as discussed above, the dog received fluid therapy prior to determination of ROTEM parameters. Hypothermia however was not present. Unfortunately, the dog did not survive to discharge. However, the dog was euthanized due to development of a septic abdomen 48 hours after presentation and not due to apparent signs of coagulopathy.

In humans, the incidence of ATC is more than 25\% in severely injured trauma patients (Brohi, et al., 2003; Maegele, et al., 2007; Frith, et al., 2010). Studies evaluating ATC in dogs are limited, with a single study describing ATC in $15 \%$ of 40 dogs with severe trauma (Holowaychuck, et al., 2014), whereas another study of 30 dogs with acute trauma did not find any signs of hypocoagulopathy at all (Abelson, et al., 2013). The most recent study described ATC in only one out of 18 dogs sustaining blunt force trauma (Gottlieb, et al., 2017). However, the incidence and outcome of ATC depends on how ATC is defined. In human medicine, several definitions of ATC exist (Brohi, et al., 2007; Frith, et al., 2010; Cohen, et al., 2013;Gonzalez, et al., 2016). Previous studies evaluating ATC in dogs have used different definitions, since there is no formal definition. Palmer suggested that every dog who sustained severe trauma with the presence of severe hypoperfusion (MAP $<60 \mathrm{mmHg}$, Base Excess $<-6 \mathrm{mmol} / 1$, Lactate $>5 \mathrm{mmol} / \mathrm{l})$, haemorrhagic shock with uncontrollable bleeding and viscoelastic tracing displaying decreased clot strength $(<40 \%$ of mean reference value) or prolonged traditional coagulation assays $(>1.5$ the labora-
Hyperfibrinolysis diagnosed with rotational thromboelastometry and treated with tranexamic acid in a dog with acute traumatic coagulopathy

B. Muri et al. 
Hyperfibrinolysis diagnosed with rotational thromboelastometry and treated with tranexamic acid in a dog with acute traumatic coagulopathy

B. Muri et al. tory mean) is highly suggestive of ATC (Palmer and Martin, 2014). Our dog showed the clinical signs of hypoperfusion described by Palmer but only a 13\% reduction in MCF. However, it showed hyperfibrinolysis, which seems to be an important factor in the pathogenesis of ATC which is not included in Palmer's definition. Diagnosing hyperfibrinolysis using ROTEM is not very sensitive, but if it is diagnosed in trauma patients, mortality ranges up to $60-70 \%$ (Schöchl, et al., 2009). Based on human data we strongly believe that the combination of hypocoaguability and hyperfibrinolysis in thromboelastometry is a distinct if not unique sign of ATC.

\section{Conclusion}

This case report describes a severely polytraumatised dog with thromboelastographic signs of hypocoaguability and hyperfibrinolysis, which resembles thromboelastographic signs of ATC in humans. Hyperfibrinolysis and hypocoagubility was successfully treated with the described management including administration of tranexamic acid. Further studies investigating hyperfibrinolysis in dogs with trauma and with suspected ATC are needed.

\section{Acknowledgements}

The authors would like to thank the SVK-ASMPA, The Swiss Association for Small Animal Medicine as well as the Stiftung für Kleintiere, which both founded a major part of our work and research.

worth S., Brohi K.: Functional definition and characterization of acute traumatic coagulopathy. Crit. Care Med. 2011, 39: 2652-2658.

Abelson A.L., O'Toole T.E. Johnston A., Respess M., Laforcade A.M.: Hypoperfusion and acute traumatic coagulopathy in severely traumatized canine patients. J. Vet. Emerg. Crit. Care 2013, 23: 395-401.

Adamik K., Butty E., Howard J.: In vitro effects of $3 \%$ hypertonic saline and $20 \%$ mannitol on canine whole blood coagultion and platelet function. BMC Vet. Res. 2015, 11: 1-7.

Brohi K., Cohen M., Ganter M., Schultz M., Levi M., Mackersie R., Pittet J.: Acute Coagulopathy of Trauma: Hypoperfusion Induces Systemic Anticoagulation and Hyperfibrinolysis. J. Trauma Inj. Infect. Cirit. Care 2008, 64: 1211-1217.

Brohi K., Singh J., Heron M., Coats T..: Acute Traumatic Coagulopathy. J. Trauma Inj. Infect. Crit. Care 2003, 54: 1127-1130.

Brohi K., Cohen M., Davenport R.: Acute Traumatic Coagulopathy: Initiated by hypoperfusion Modulated through the Protein C Pathway? Ann. Surg. 2007, 245: 812-818.

Brohi K., Cohen M., Davenport R.: Acute coagulopathy of trauma: mechanism, identification and effect. Curr. Opin. Crit. Care 2007, 13: 680-685

Cardenas J., Matijevic N., Baer L., Holcomb J., Cotton B., Wade $C$.: Elevated tissue plasminogen activator and reduced plasminogen activator inhibitor promote hyperfibrinolysis in trauma patients. Shock 2014, 41: 514-521.

Cohen M. J. And the PROMMTT Study Group: Clinical and mechanistic drivers of acite traumatic coagulopathy. J. Trauma Acute Care Surg. 2013, 75: S40-S47.

CRASH-2 trial collaborators: Effects of tranexamic acid on death, vascular occlusive events, and blood transfusion in trauma patients with significant haemorrhage (CRASH-2): a randomised, placebo-controlled trial. Lancet 2010, 376: 23-32.

Davenport R., Manson J., De'Ath H., Platton S., Coates A., Allard S., Hart D. ,Pearse R., Pasi J., MacCallum P., Stan-
Davenport R.,Brohi K.: Cause of trauma-induced coagulopathy. Curr. Opin. Anesthesiol. 2016, 29: 212-219.

Dirkmann D., Hanke A., Görlinger K., Peters J.: Hypothermia and Acidosis Synergistically Impair Coagulation in Human Whole Blood. Anesth. Analg. 2008, 106: 1627-1632.

Dobson G., Letson H., Sharma R., Sheppard F., Cap A.: Mechanisms of early trauma-induced coagulopathy: The clot thickens or not? J. Trauma Acute Care Surg. 2015, 79: 301-309.

Engstrom M., Schott U., Nordstrom C.H., Romner B., Reinstrup P.: Increased Lactate Levels Impair the Coagulation System - A Potential Contributin Factor to Progessive Hemorrhage After Traumatic Brain Injury. J. Neurosurg. Anesthesiol. 2006, 18: 200-204.

Fletcher D, Rozanski E., Brainard B., de Laforcade A., Brooks $M .:$ Assessment of the relationships among coagulopathy, hyperfibrinolysis, plasma lactate, and protein $C$ in dogs with spontaneous hemoperitoneum. J. Vet. Emerg. Crit. Care 2015, 0: 1-11.

Frith D., Goslings J., Gaarder C., Maegele M., Cohen J, Allard S, Johansson P.I., Stanworth S., Thiemermann C., Brohi K.: Definition and drivers of acute traumatic coagulopathy: clinical and experimental investigations. J.Thromb. Haemost. 2010, 8: 1919-1925.

Ganter M.,Hofer C.: Coagulation Monitoring: Current Techniques and Clinical Use of Viscoelastic Point-of-Care Coagulation Devices. Anaesth. Analg. 2008, 106: 1366-1375.

Gonzalez E., Moore E., Moore H., Chapmann M., Chin T., Ghasabyan A., Wohlauer M., Barnett C., Bensard D., Biffl W., Burlew C., Johnson J., Pieracci F., Jurkovich G., Banerjee A., Silliman C., Sauaia A.: Goal-directed Hemostatic Resuscitation of Trauma-induced Coagulopathy. Ann. Surg. 2016, 263: 1051-1059. 
Gottlieb D., Pittie J., Buriko Y., Lamb K.: Evaluation of acute traumatic coagulopathy in dogs and cats following blunt force trauma. J. Vet. Emerg. Crit. Care 2017, 27: 35-43.

Hagemo J., Christiaans S., Stanworth S., Brohi K., Johansson P., Goslings J., Naess P., Gaarder C.: Detection of acute traumatic coagulopathy and massive transfusion requirements by means of rotational thromboelastometry: an international prospective validation study. J. Crit. Care 2015, 19: 1-7

Holowaychuck M., Hanel R., Wood R., Rogers L., O'Keefe K., Monteith G.: Prospective multicenter evaluation of coagulation abnomalities in dogs following severe acute trauma. J. Vet. Emerg. Crit. Care 2014, 24: 93-104.

MacLeod J., Lynn M., McKenney M., Cohn s., Murtha M.: Early Coagulopathy predicts Mortality in Trauma. J. Trauma Inj. Infect. Crit. Care 2003, 55: 39-44.

Maegele M., Lefering R., Yucel N., Tjardes T., Rixen D., Paffrath T., Simanski C., Neigebauer E., Boullon B.: Early coagulopathy in multiple injury: An analysis from the German Trauma Registry on 8724 patients. Int. J. Care Inj. 2007, 38: 298-304.

Mischke R.: Acute haemostatic changes in accidentally traumatised dogs. Vet. J. 2005, 169: 60-64

Palmer L., Martin L.: Traumatic coagulopathy-Part 1: Pathophysiology and diagnosis. J. Vet. Emerg. Crit. Care 2014, 24: 63-74.

Raza I., Davenport R., Rourke C., Platton S., Manson J, Spoors C., Khan S., De'Ath H., Allard S., Hart D., Pasi K., Hunt J., Stanworth S. ,MacCallum P., Brohi K.: The incidence and magnitude of fibrinolytic activation in trauma patients. J. Thromb. Haemost. 2013, 11: 307-314.

Reuteler A., Axiak-Flammer S., Howard J., Adamik K.: Comparison of the effects of a balanced crystalloid-based and a saline-based tetrastarch solution on canine whole blood coagulation and platelet function. J. Vet. Emerg. Crit. Care 2017, 27: 23-34.

Rockar R., Drobatz K., Shofer F.: Development Of A Scoring System For The Veterinary Trauma Patient. J. Vet. Emerg. Crit. Care 1994, 4: 77-83.

Rossaint R., Bouillon B., Cerny V., Coats T., Duranteau J., Fernández-Mondéjar E., Filipescu D., Hunt B., Komadina R., NArdi G., Neugebauer E., Ozier Y., Riddez L. Schultz A., Vincent J.L., Spahn D.: The European guideline on management of major bleeding and coagulopathy following trauma: fourth edition. Crit. Care 2016, 20: 1-55.

Schöchl H., Frietsch T., Pavelka M., Jámbor C.: Hyperfibrinolysis after major trauma: Differential diagnosis of lysis patterns and prognostic value of thrombelastometry. J. Trauma Inj. Infect. Crit. Care 2009, 67: 125-131.

Sigrist N., Hofer-Intewoorm N., Jud-Schefer R., Kuemmerle-Fraune C., Schnyder M., Kutter A.: Hyperfibrinolysis and Hypofibrinogenemia diagnosed with Rotational Thromboelastometry in Dogs naturally infected with Angiostrongylus vasorum. J. Vet. Intern. Med. 2017, 31: 1091-1099

Spiel A., Mayr F., Firbas C., Quehenberger P., Jilma B.: Validation of rotation thrombelastography in a model of systemic activation of fibrinolysis and coagulation in humans. J. Thromb. Haemost. 2006, 4: 411-416.

Yoo S., Venn E., Sullivan L., Olver C.: Thromboelastographic evidence of inhibition of fibrinolysis after e-aminocaproic acid administraiton in a dog with suspected acute traumatic coagulopathy. J. Vet. Emerg. Crit. Care 2016, 00: 1-6.

\section{Corresponding author}

Benjamin Muri

Department for Small Animals

Vetsuisse Faculty

University of Zurich

Switzerland

E-Mail: bmuri@vetclinics.uzh.ch
Hyperfibrinolysis diagnosed with rotational thromboelastometry and treated with tranexamic acid in a dog with acute traumatic coagulopathy

B. Muri et al. 